\title{
Hyperthermia enhances mapatumumab-induced apoptotic death through ubiquitin-mediated degradation of cellular FLIP(long) in human colon cancer cells
}

\author{
X Song ${ }^{1}$, S-Y Kim ${ }^{1}$, Z Zhou ${ }^{2}$, E Lagasse ${ }^{3}$, YT Kwon ${ }^{4,5}$ and YJ Lee ${ }^{\star, 1,6}$
}

Colorectal cancer is the third leading cause of cancer-related mortality in the world; the main cause of death of colorectal cancer is hepatic metastases, which can be treated with hyperthermia using isolated hepatic perfusion (IHP). In this study, we report that mild hyperthermia potently reduced cellular FLIP(long), (c-FLIP $)$, a major regulator of the death receptor (DR) pathway of apoptosis, thereby enhancing humanized anti-DR4 antibody mapatumumab (Mapa)-mediated mitochondria-independent apoptosis. We observed that overexpression of $C-F L I P_{L}$ in CX-1 cells abrogated the synergistic effect of Mapa and hyperthermia, whereas silencing of $c$-FLIP in CX-1 cells enhanced Mapa-induced apoptosis. Hyperthermia altered C-FLIPL protein stability without concomitant reductions in FLIP mRNA. Ubiquitination of $C-F L I P L$ was increased by hyperthermia, and proteasome inhibitor MG132 prevented heat-induced downregulation of C-FLIP $P_{L}$. These results suggest the involvement of the ubiquitinproteasome system in this process. We also found lysine residue 195 (K195) to be essential for C-FLIPL ubiquitination and proteolysis, as mutant C-FLIP $P_{L}$ lysine 195 arginine (arginine replacing lysine) was left virtually un-ubiquitinated and was refractory to hyperthermia-triggered degradation, and thus partially blocked the synergistic effect of Mapa and hyperthermia. Our observations reveal that hyperthermia transiently reduced C-FLIP $\mathrm{L}_{\mathrm{L}}$ by proteolysis linked to K195 ubiquitination, which contributed to the synergistic effect between Mapa and hyperthermia. This study supports the application of hyperthermia combined with other regimens to treat colorectal hepatic metastases.

Cell Death and Disease (2013) 4, e577; doi:10.1038/cddis.2013.104; published online 4 April 2013

Subject Category: Cancer

Colorectal cancer is the third leading cause of cancer-related mortality in the world. The main cause of death of patients with colorectal cancer is hepatic metastases. Approximately $25 \%$ of patients with colorectal cancer will develop metastatic disease exclusively or largely confined to the liver. Untreated patients with liver metastases share a poor prognosis, with an average survival of 12 months. In contrast, patients whose liver metastatic lesions are surgically treated have an average 5 -year survival rate of $40 \%$, but only $10-15 \%$ of initial colorectal liver metastases are considered resectable. ${ }^{1}$ The unresectable cases of liver metastatic disease can be treated with isolated hepatic perfusion (IHP), which involves a method of complete vascular isolation of the liver to allow for combinational treatment of liver tumors. ${ }^{2-5}$

Mapatumumab (Mapa) is a fully human IgG1 agonistic monoclonal antibody, which exclusively targets and activates death receptor (DR) 4 with high specificity and affinity. ${ }^{6,7}$ Apoptosisinducing mechanisms of Mapa are thought to be similar to apoptosis mediated by TNF-related apoptosis-inducing ligand (TRAIL). Briefly, Mapa binds to the cell surface of DR4 and triggers the extrinsic apoptotic pathway, mainly through the activation of the pro-apoptotic initiator caspase 8. Mapa is a promising anticancer agent because of its ability to induce apoptosis selectively in cancer cells, and thus has a safety profile. However, phase-II trials showed no/little clinical activity of single-agent Mapa in patients with advanced refractory colorectal cancer or non-small cell lung cancer. ${ }^{8}$ The resistance may occur at different points in the signaling pathways by dysfunctions of the DR4 and DR5, defects in Fas-associated death domain (FADD), overexpression of anti-apoptotic proteins, or loss of pro-apoptotic proteins. ${ }^{9}$ It is therefore critical to develop applicable strategies to overcome this resistance.

\footnotetext{
${ }^{1}$ Department of Surgery, University of Pittsburgh, Pittsburgh, PA, USA; ${ }^{2}$ Department of Cell Biology and Physiology, University of Pittsburgh, Pittsburgh, PA, USA; ${ }^{3}$ Department of Pathology, McGowan Institute for Regenerative Medicine, University of Pittsburgh School of Medicine, Pittsburgh, PA, USA; ${ }^{4}$ World Class University (WCU) Program, Department of Molecular Medicine and Biopharmaceutical Sciences, Graduate School of Convergence Science and Technology and College of Medicine, Seoul National University, Seoul, Korea; ${ }^{5}$ Center for Pharmacogenetics and Department of Pharmaceutical Sciences, School of Pharmacy, University of Pittsburgh, Pittsburgh, PA, USA and ${ }^{6}$ Department of Pharmacology and Chemical Biology, School of Medicine, University of Pittsburgh, Pittsburgh, PA, USA *Corresponding author: YJ Lee, Department of Surgery, University of Pittsburgh, Hillman Cancer Center, 5117 Centre Avenue Room 1.46C, Pittsburgh, PA 15213, USA. Tel: (412) 623 3268; Fax: (412) 623 7709; E-mail: leeyj@upmc.edu

Keywords: hyperthermia; mapatumumab; mitochondria-independent pathway; ubiquitination; C-FLIPL

Abbreviations: aa, amino acid; DR, death receptor; CHX, cycloheximide; c-FLIP, cellular FLICE-inhibitory protein; c-FLIPL, long form of c-FLIP; c-FLIPs, short form of C-FLIP; FADD, Fas-associated death domain; DISC, death-inducing signaling complex; IHP, isolated hepatic perfusion; $\mathrm{NH}_{4} \mathrm{Cl}$, ammonium chloride; Mapa, mapatumumab; PARP, poly (ADP-ribose) polymerase; ROS, reactive oxygen species; K106R, lysine 106 arginine; K195R, lysine 195 arginine; TRAIL, TNF-related apoptosis-inducing ligand; WT, wild type

Received 03.1.13; revised 21.2.13; accepted 25.2.13; Edited by M Agostini
} 
The cellular FLICE-inhibitory protein (c-FLIP) is the major inhibitor of the extrinsic apoptotic pathway through inhibition of caspase 8 activation and processing at the death-inducing signaling complex (DISC) ${ }^{10}$ Differential splicing gives rise to long form of cellular FLIP (c-FLIP $\mathrm{L}_{\mathrm{L}}$ ) and short (c-FLIP $)_{\mathrm{s}}$ forms of c-FLIP. Both c-FLIP splice variants bind to FADD within the DISC. They compete with caspase 8 for DISC association and can form heteromeric complexes with this caspase of the extrinsic pathway, thereby interfering with its proper activation with the consequence of inhibiting apoptosis. ${ }^{11,12}$ Of note, c-FLIP $\mathrm{L}_{\mathrm{L}}$ which is the most abundant isoform in many cancer cell lines, is a key regulator of colorectal cancer cell death and associated with a poor prognosis in colorectal cancer patients. ${ }^{13-15}$

Hyperthermia has been explored as an anticancer agent for many decades and is often used with IHP. Our laboratory has focused on identifying strategies and mechanisms for thermal sensitization in an attempt to improve the clinical efficacy of IHP. We previously reported that hyperthermia has a synergistic effect with Mapa or TRAIL in causing cytotoxicity through the mitochondria-dependent pathway. ${ }^{16-18}$ We report here that hyperthermia triggered downregulation of $c-F L I P_{L}$ in all tested cells, albeit at cell-specific levels. The C-FLIP downregulation subsequently sensitized to apoptosis mediated by Mapa in human colon cancer cells. Additionally, we show that the hyperthermia-induced downregulation of C-FLIP $\mathrm{P}_{\mathrm{L}}$ was due to increased ubiquitination and proteasomal degradation of $\mathrm{C}-\mathrm{FLIP} \mathrm{P}_{\mathrm{L}}$. Furthermore, for the first time, lysine residue 195 (K195) was found essential for C-FLIP $\mathrm{P}_{\mathrm{L}}$ ubiquitination and proteolysis, and contributed to the synergistic effect of Mapa and hyperthermia. Our findings indicate that hyperthermia augmented Mapa-induced apoptotic death through ubiquitin-mediated degradation of cellular FLIP $P_{L}$ in human colon cancer cells.

\section{Results}

Hyperthermia enhanced Mapa-induced apoptosis in human colorectal cancer $\mathrm{CX}-1$ cells. To investigate the effect of hyperthermia on Mapa-induced cytotoxicity, the cell viability was determined by MTS assay. CX-1 cells were heated $\left(42^{\circ} \mathrm{C}\right.$ for $\left.1 \mathrm{~h}\right)$ in the absence or presence of various concentrations of Mapa $(10-1000 \mathrm{ng} / \mathrm{ml})$ and incubated at $37^{\circ} \mathrm{C}$ for $72 \mathrm{~h}$, as shown in Figure 1a. Synergistic effect was observed in hyperthermia combined with Mapa in a dosedependent manner. To clarify whether the effect of hyperthermia on Mapa-induced cytotoxicity is associated with apoptosis, CX-1 cells were heated $\left(42^{\circ} \mathrm{C}\right.$ for $\left.1 \mathrm{~h}\right)$ in the absence or presence of $100 \mathrm{ng} / \mathrm{ml}$ Mapa and incubated at $37^{\circ} \mathrm{C}$ for $3 \mathrm{~h}$, and flow cytometric assays were performed. Figure $1 \mathrm{~b}$ clearly shows that hyperthermia enhanced Mapainduced apoptotic death. Enhancement of apoptosis was also detected by cell cycle studies. The analysis of cell cycle distribution revealed that Mapa treatment alone resulted in an S-phase arrest and sub-G1 (apoptosis) phase accumulation, whereas hyperthermia in combination with Mapa significantly increased sub-G1 phase (Figure 1c). We then examined the effect of different temperatures of hyperthermia on Mapa-induced apoptosis. Figure 1d indicates that treatment of cells with Mapa resulted in caspase 8 and 3 activation (cleavage), and thus poly (ADP-ribose) polymerase (PARP) cleavage (the hallmark feature of apoptosis). Interestingly, hyperthermia promoted the activation of caspase 8 (mitochondria-independent pathway), caspase 9 (mitochondria-dependent pathway) and caspase 3 as well as PARP cleavage during treatment with Mapa. Similar results were obtained in human colon cancer stem cells Tu-12, Tu-21 and Tu-22 (Figure 1e). As we have previously shown how hyperthermia enhanced Mapa-induced apoptosis through the mitochondria-dependent pathway, ${ }^{18}$ in this study we focused on how hyperthermia enhanced Mapainduced apoptosis through the mitochondria-independent pathway.

C-FLIP level was dramatically reduced following hyperthermia on human colorectal cancer cells as well as colon cancer stem cells. c-FLIP is the major inhibitor of the extrinsic apoptotic pathway through inhibition of caspase 8 activation, and we observed that the level of $c-F_{L} P_{L}$ was reduced after hyperthermia at $41-43^{\circ} \mathrm{C}$ for $1 \mathrm{~h}$ (Figure 2a) and as long as $1-4 \mathrm{~h}$ (Figure $2 \mathrm{~b}$ ) in human colon carcinoma CX-1 cells. We also investigated whether this paradigm could be applicable for colon cancer stem cells (Tu-12, Tu-21 and Tu-22); Figure $2 c$ reveals a similar reduction of the level of c-FLIP $\mathrm{P}_{\mathrm{L}}$ in response to temperature-dependent hyperthermia in human colon cancer stem cells. We also observed this phenomenon in mouse embryonic fibroblast (MEF) cells (Figure 6c), breast cancer cells (Figure 6d) and head and neck cancer cells (data not shown), which indicated that hyperthermia markedly reduced $\mathrm{C}-\mathrm{FLIP}_{\mathrm{L}}$ in all tested cells, albeit at cell-specific levels.

The synergistic effect of hyperthermia on Mapa-induced apoptosis is correlated with the intracellular level of c-FLIP $\mathbf{P}_{\mathbf{L}}$ in various colon cancer cell lines. Western blot showed that the hyperthermia-induced decrease in the C-FLIP $\mathrm{L}$ levels was restored within $3 \mathrm{~h}$ during recovery at $37^{\circ} \mathrm{C}$ (Figure 3a). Therefore, we investigated whether the intracellular levels of $C-F L I P_{L}$ correlated with the hyperthermia-induced sensitization to Mapa-mediated apoptosis. Mapa was either treated with hyperthermia simultaneously, or 0-3 $\mathrm{h}$ after hyperthermia recovery. The kinetics of c-FLIP reduction and restoration corresponded to the kinetics of hyperthermia-mediated sensitization and desensitization to Mapa-mediated apoptosis (Figure 3b). To further determine the relationship between the synergistic effect of hyperthermia on Mapa-induced apoptotic death and the expression of $\mathrm{C}-\mathrm{FLIP}_{\mathrm{L}}$, we examined the correlation between cell death by treatment with Mapa plus hyperthermia and their intracellular levels of C-FLIP in CX-1, HCT116, Tu-22 and HT29 cells. Cell viability and C-FLIPL levels of these cell lines were detected by MTS assay and immunoblotting assay, respectively (Figure 3c). HCT116 had the lowest level of $C-F L I P_{L}$ and showed the highest cell killing by Mapa plus hyperthermia, whereas Tu-22 had the highest c-FLIP $\mathrm{L}_{\mathrm{L}}$ level and exhibited minimal cell death. Cell killing by Mapa plus hyperthermia was plotted as a function of relative level of c-FLIP $P_{L}$ (c-FLIP $/$ actin) (Figure 3d). The correlation coefficient was calculated to be $0.817(P<0.05)$, which indicates a significant negative correlation (Figure 3d). Collectively, 


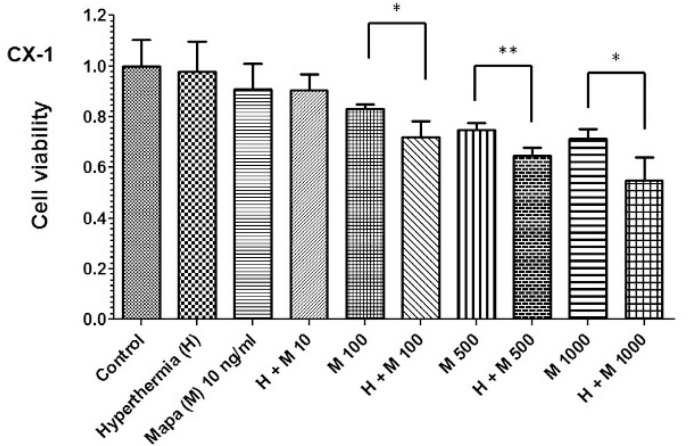

d

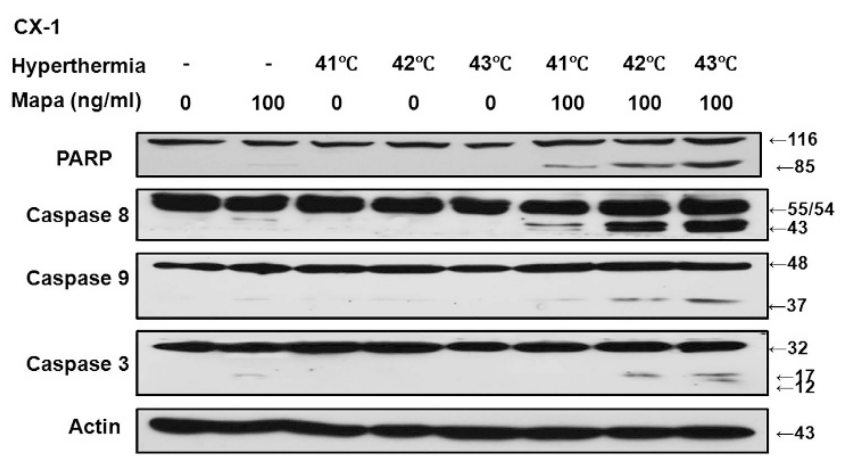

e

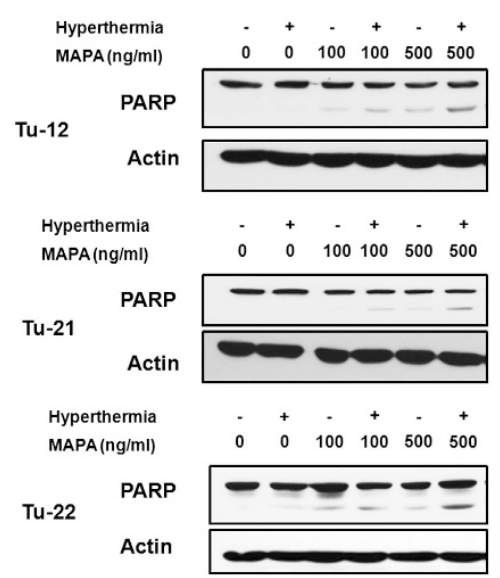

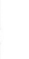
0 b

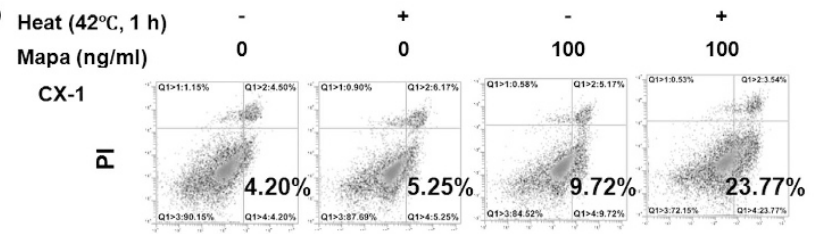

Annexin V

\section{C}

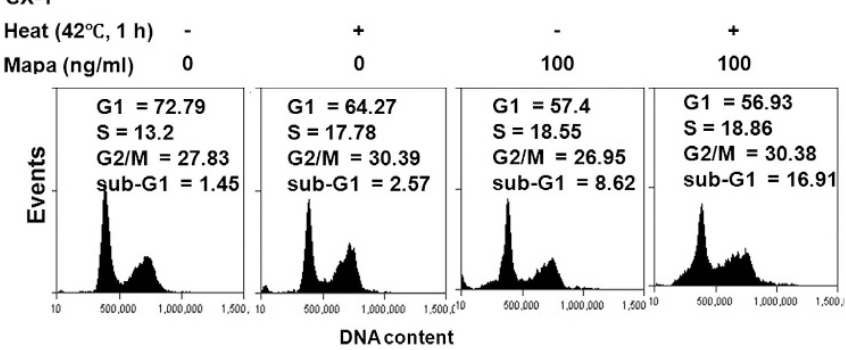


a

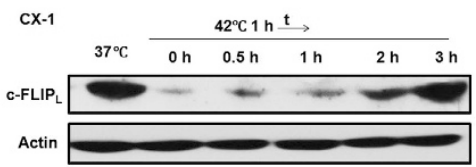

b

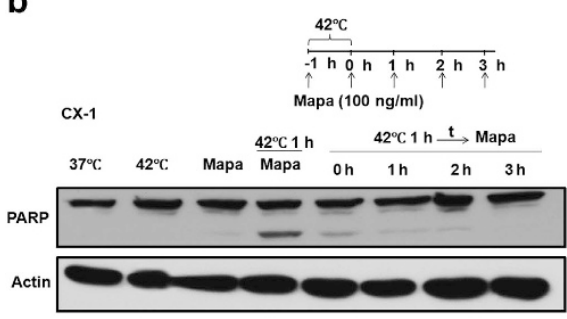

C
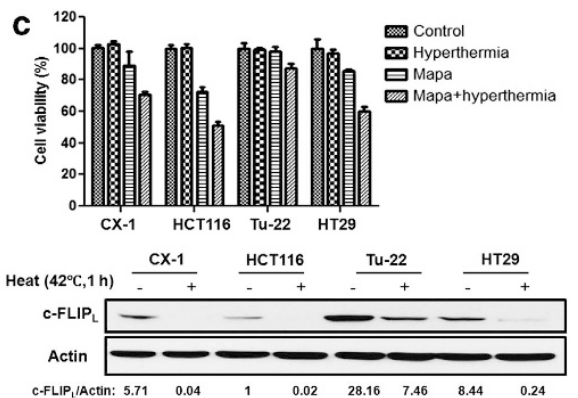

d

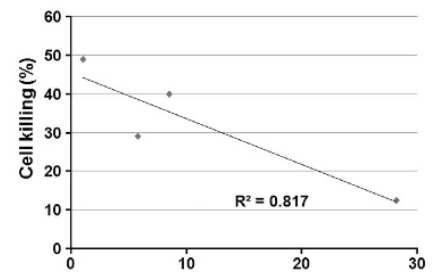

Figure 3 Hyperthermia-induced downregulation of C-FLIPL was associated with sensitization to Mapa-mediated apoptosis. (a) CX-1 cells were subjected to 1-h hyperthermia treatment at $42^{\circ} \mathrm{C}$ and then left to recover for $0.5,1,2$ and $3 \mathrm{~h}$. The level of $\mathrm{c}-\mathrm{FLIP} \mathrm{L}$ was examined by western blot. Equal loading was controlled with actin. (b) Mapa was either added simultaneously with hyperthermia at $42^{\circ} \mathrm{C}$ for $1 \mathrm{~h}$ and incubated at $37^{\circ} \mathrm{C}$ for $3 \mathrm{~h}$, or added $0,1,2$, or $3 \mathrm{~h}$ after heat recovery and then incubated at $37^{\circ} \mathrm{C}$ for $4 \mathrm{~h}$. PARP was examined by western blot. Actin was used as a loading control. (c) Upper panel: CX-1, HCT116, Tu-22 and HT29 cells were heated at $42{ }^{\circ} \mathrm{C}$ for $1 \mathrm{~h}$ in the presence or absence of $100 \mathrm{ng} / \mathrm{ml}$ Mapa, and then incubated for $72 \mathrm{~h}$ at $37^{\circ} \mathrm{C}$. Cell viability was analyzed by MTS assay. Error bars represented S.D. from triplicate experiments. Lower panel: these cells were collected and lysed after being heated at $42{ }^{\circ} \mathrm{C}$ for $1 \mathrm{~h}$. Cell lysates were subjected to western blot for $\mathrm{C}-\mathrm{FLIP} \mathrm{P}_{\mathrm{L}}$. The densities of bands were analyzed using Gel-pro application from Media Cybernetics (Rockville, MD, USA). (d) Cell killing was plotted as a function of relative c-FLIP $P_{L}$ level. The Spearman's correlation coefficient between relative levels of c-FLIP $P_{L}$ and cell killing by Mapa + hyperthermia was calculated to be $0.817(P<0.05)$ using SPSS15.0 software
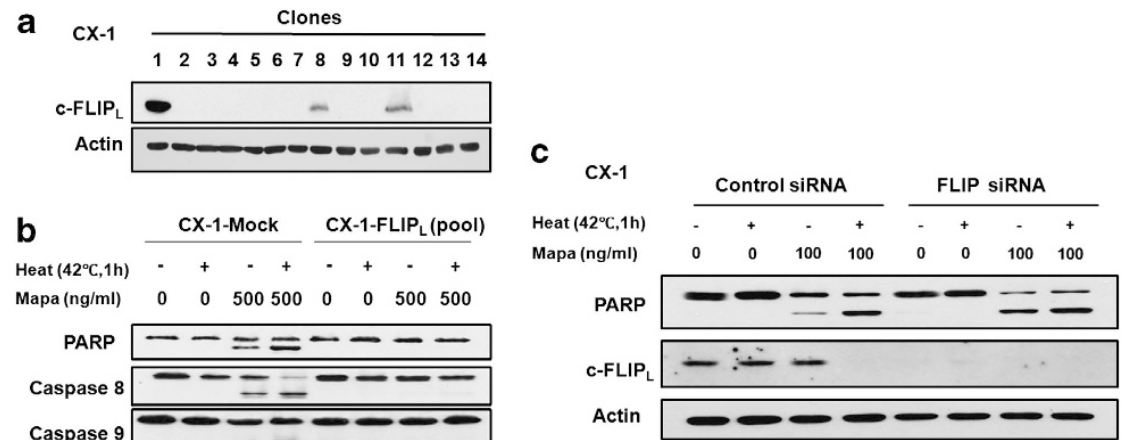

Figure 4 c-FLIP was responsible for the synergistic effect of Mapa and hyperthermia. (a) CX-1 cells were transfected with pCR3.V64-Met-Flag-FLIPL and stable clones were selected with G418 (500 $\mu \mathrm{g} / \mathrm{ml})$. (b) Control plasmid or pCR3.V64-Met-Flag-FLIPL stably transfected cells from a pool of clone $1 \#, 8 \#$ and $11 \#$ were heated at $42^{\circ} \mathrm{C}$ for $1 \mathrm{~h}$ in the presence or absence of $500 \mathrm{ng} / \mathrm{ml}$ Mapa, and then incubated at $37^{\circ} \mathrm{C}$ for $3 \mathrm{~h}$. The level of $\mathrm{C}-\mathrm{FLIP}$ and the cleavage of caspase 8 , caspase 9 and PARP were detected by immunoblotting. Actin was used as loading control. (c) CX-1 cells were transfected with nonsense sequence (control) or FLIP siRNA-targeting FLIP mRNA. After $48 \mathrm{~h}$, cells were heated at $42{ }^{\circ} \mathrm{C}$ for $1 \mathrm{~h}$ in the presence or absence of $100 \mathrm{ng} / \mathrm{ml}$ Mapa, and then incubated for $3 \mathrm{~h}$. The levels of c-FLIPL and PARP were detected by immunoblotting. Actin was used as a loading control

hyperthermia-induced apoptosis, we created $\mathrm{CX}-1-\mathrm{FLIPL}$ cell lines that stably overexpress $C-F L I P L$ in $C X-1$ cells (Figure 4a). As shown in Figure 4b, overexpression of FLIP protected cells from Mapa- and hyperthermia-induced apoptosis. In contrast, knockdown of FLIP by smallinterfering RNA (siRNA) significantly enhanced Mapainduced apoptosis (Figure 4c). Of note, the synergistic effect of hyperthermia on Mapa-induced apoptosis was abolished by FLIP siRNA, as FLIP level was already decreased by hyperthermia (Figure 2a), thereby confirming an important role of $c-F L I P L$ in the synergistic effect of hyperthermia on Mapa-induced apoptosis (Figure 4c).
Hyperthermia enhanced ubiquitination and proteasomal degradation of C-FLIP $\mathrm{L}_{\mathrm{L}}$. We then explored the mechanisms by which hyperthermia decreased the level of $c-F L I P_{L}$. Quantitative reverse transcription -PCR (qRT-PCR) was performed to examine the involvement of de novo synthesis of c-FLIP mRNA in this process. No significant inhibition of c-FLIP expression at the mRNA level was evident after hyperthermia (Figure 5a). Next, we examined whether hyperthermia-induced inhibition of protein synthesis is responsible for hyperthermia-induced downregulation of C-FLIP . Heat shock at $42^{\circ} \mathrm{C}$ for $1 \mathrm{~h}$ inhibited protein synthesis by $65 \%$ (data not shown). However, data from 
a

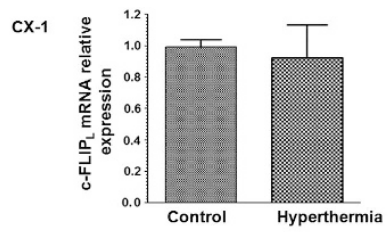

b

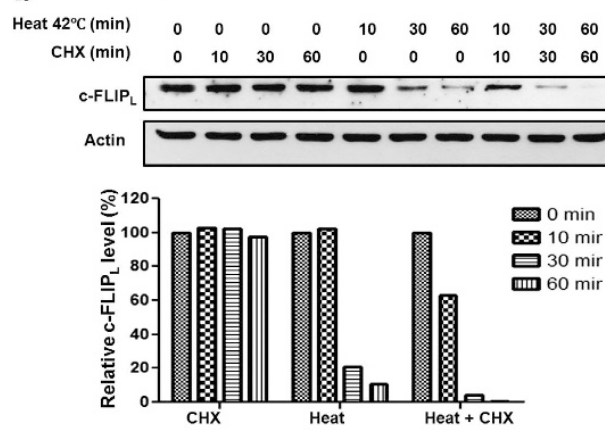

c

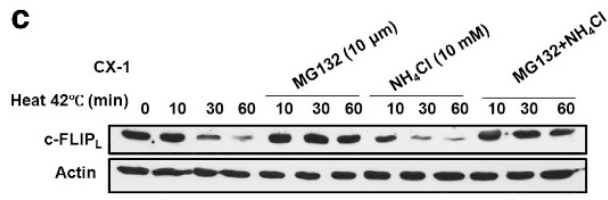

HCT116
Heat $42^{\circ} \mathrm{C}(\min )$
C-FLIP e

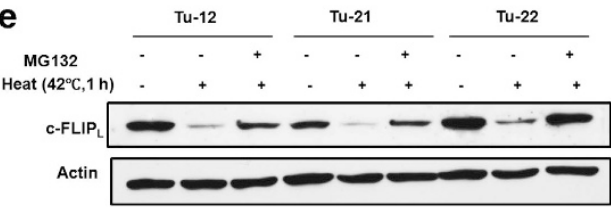

f

CX-1

$M G 132(\min ):-\quad-\quad-\quad 30 \quad 60 \quad 30 \quad 60$

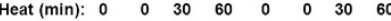

IP: IgG ub ub ub ub ub ub ub

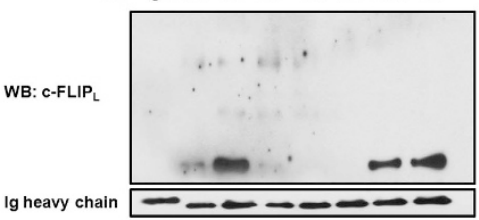

g

CX-1

MG132(min) : - - - - $30 \quad 60 \quad 30 \quad 60$

Heat $(\mathrm{min}): 0 \quad 0 \quad 30 \quad 60 \quad 0 \quad 0 \quad 30 \quad 60$

IP: IgG FLIP FLIP FLIP FLIP FLIP FLIP FLIP

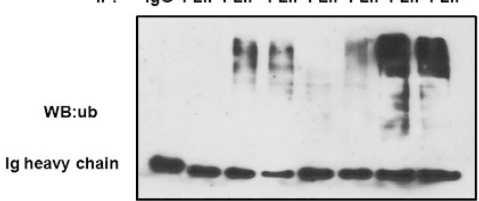

Input:

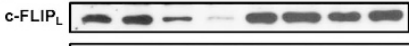

Actin $-\infty-\infty-\infty$

Figure 5 The ubiquitination and proteasomal degradation of c-FLIP were increased upon hyperthermia. (a) qRT-PCR was performed on CX-1 cells exposed to hyperthermia at $42^{\circ} \mathrm{C}$ for $1 \mathrm{~h}$ to measure the relative c-FLIP mRNA level. The bar graph represented mean values ( \pm S.D.) from triplicate experiments. (b) CX-1 cells were treated with $30 \mu \mathrm{g} / \mathrm{ml} \mathrm{CHX}$, or exposed to hyperthermia at $42^{\circ} \mathrm{C}$ in the presence or absence of $\mathrm{CHX}$. The levels of C-FLIP and loading control actin were measured by western blot analysis. The densities of bands were analyzed using Gel-pro application. (c) CX-1 cells were exposed to hyperthermia for $10 \mathrm{~min}, 30 \mathrm{~min}$ and $60 \mathrm{~min}$ in the presence or absence of MG132 or/and $\mathrm{NH}_{4} \mathrm{Cl}$; c-FLIP $\mathrm{L}_{\mathrm{L}}$ was measured by western blot analysis. (d) HCT116 cells were exposed to hyperthermia for $10 \mathrm{~min}, 30 \mathrm{~min}$ or 60 min in the presence or absence of MG132, and then C-FLIP $P_{L}$ was detected by western blot. (e) Tu-12, Tu-21 and Tu-22 cells were heated for $1 \mathrm{~h}$ in the presence or absence of MG132, and $C-F L I P_{L}$ was examined by western blot. Actin was used as a loading control. $(\mathbf{f}, \mathbf{g})$ CX-1 cells were exposed to hyperthermia for 30 or 60 min in the presence or absence of MG132. Lysate samples were immunoprecipitated with anti-ubiquitin (f) or NF6 (g) antibody, and then immunoblotted with NF6 (f) or anti-ubiquitin (g) antibody. The presence of heavy chain of IgG was shown in lower panel (f). The presence of C-FLIPL or actin in the lysates was verified by immunoblotting $(\mathbf{g})$

immunoblot assays and densitometer tracings of immunoblots show that protein synthesis inhibitor cycloheximide $(\mathrm{CHX}, 30 \mu \mathrm{g} / \mathrm{ml})$, which inhibits protein synthesis by $99 \%$, didn't significantly reduce the intracellular level of $\mathrm{C}-\mathrm{FLIP}_{\mathrm{L}}$ (Figure $5 \mathrm{~b}$ ). These results suggest that protein synthesis inhibition is not responsible for downregulation of FLIP $L$. The other possibility is that $\mathrm{C}-\mathrm{FLIP}_{\mathrm{L}}$ is a thermolabile protein and easily denatured and subsequently degraded during hyperthermia. It is well known that the intracellular degradation of protein occurs in two ways - proteolysis in lysosome and an ubiquitin-dependent process, which targets proteins to proteasome. ${ }^{19}$ Indeed, several studies show that C-FLIPL is degraded via the proteasome or lysosome pathway. ${ }^{20,21}$ To verify which pathway was involved in hyperthermiainduced downregulation of $C-F_{L} P_{L}$, we used the proteasome inhibitor MG132 and lysosomal proteases inhibitor ammonium chloride $\left(\mathrm{NH}_{4} \mathrm{Cl}\right)$. Figure $5 \mathrm{c}$ shows that treatment with MG132, but not $\mathrm{NH}_{4} \mathrm{Cl}$, restored $\mathrm{C}-\mathrm{FLIP}_{\mathrm{L}}$ expression completely, confirming the existence of proteasome-mediated degradation of the protein, whereas lysosome-mediated degradation was not involved. Similar results were obtained in HCT116 cells (Figure $5 \mathrm{~d}$ ) and cancer stem cells of Tu-12, Tu-21 and Tu-22 (Figure 5e). Ubiquitination assays in Figures $5 f$ and $g$ confirmed that the ubiquitination of endogenous $C-F_{L} P_{L}$ increased upon hyperthermia treatments. Moreover, proteasome inhibitor MG132 blocked the degradation of $C-F L I P_{L}$; thus, more ubiquitinated $C-F L I P_{L}$ was accumulated (Figure $5 \mathrm{~g}$ ). Collectively, these results showed that degradation of $\mathrm{C}-\mathrm{FLIP} \mathrm{L}$ after hyperthermia occurs through the proteasomal pathway, which regulates the intracellular level of this protein.

Hyperthermia-induced $C-F L I P_{L}$ degradation is independent of the Itch and UBR1/2 E3 ligases, reactive oxygen species (ROS), JNK and HSP90. Several researchers have reported that c-FLIP expression is regulated by JNKmediated phosphorylation and activation of E3 ubiquitin ligase (Itch). ${ }^{22-24}$ To examine whether Itch has a role in hyperthermia-induced downregulation of $\mathrm{c}-\mathrm{FLIP}_{\mathrm{L}}$, we generated Itch-knockdown $\mathrm{CX}-1$ cell by infection with lentiviral 

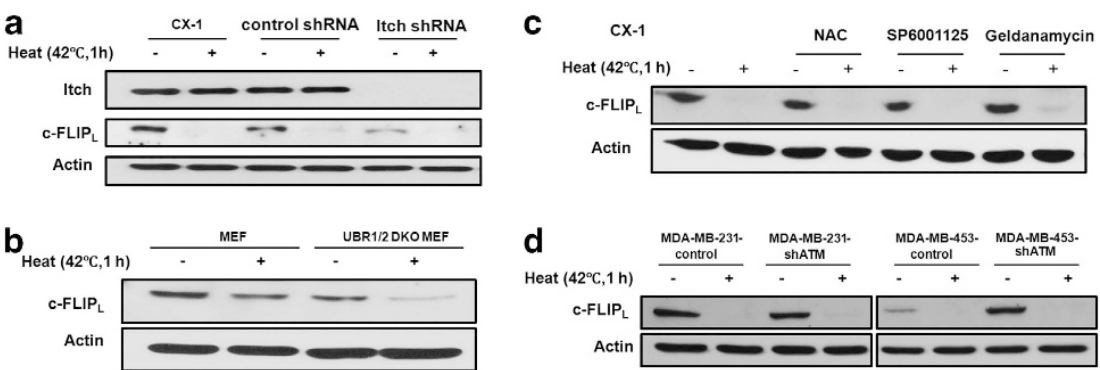

Figure 6 Hyperthermia-induced downregulation of C-FLIP $L_{L}$ was not associated with Itch and UBR1/2 E3 ligases, oxidative stress, JNK activation, HSP90 activity, and DNA damage. (a) CX-1 mock cells and its Itch shRNA cells were treated at $42{ }^{\circ} \mathrm{C}$ for $1 \mathrm{~h}$, and the levels of Itch and c-FLIP $\mathrm{P}_{\mathrm{L}}$ were measured by western blot analysis. Equal loading was confirmed with actin. (b) MEF and its UBR1/2 DKO (ubiquitin-protein ligase E3 component N-recognin 1 and 2 double knockout) cells were treated at $42^{\circ} \mathrm{C}$ for $1 \mathrm{~h}$, and the level of C-FLIP was measured by western blot analysis. Equal loading was confirmed with actin. (c) CX-1 cells were treated at $42{ }^{\circ} \mathrm{C}$ in the presence or absence of NAC, SP6001125 or geldanamycin. The level of C-FLIP ${ }_{L}$ and loading control actin were measured by western blot analysis. (d) Breast cancer MDA-MB-231, MDA-MB-453 and their ATM was knocked down by ATM shRNA (shATM). Cells were heated at $42{ }^{\circ} \mathrm{C}$ for $1 \mathrm{~h}$ and then the level of C-FLIPL was examined by western blot analysis. Equal loading was confirmed with actin

vector-containing Itch short hairpin RNA (shRNA) (Figure 6a). We observed that significant knockdown of Itch did not prevent the downregulation of $\mathrm{C}-\mathrm{FLIP}_{\mathrm{L}}$ during hyperthermia (Figure 6a). We also examined whether ubiquitin-protein ligase E3 components $\mathrm{N}$-recognin 1 and 2 (UBR1/2) are involved in the heat-induced downregulation of C-FLIP , by employing UBR1/2 double knockout (DKO) MEF. Data from Figure $6 \mathrm{~b}$ shows that UBR1 and UBR2 are unlikely to be involved in the ubiquitination of $C$-FLIPL. Several researchers have reported that $\mathrm{ROS}$ and ataxia telangiectasia mutated (ATM) kinase regulate c-FLIP expression level. ${ }^{25-27}$ It is possible that ROS and its associated signals are involved in downregulation of $\mathrm{C}-\mathrm{FLIP}_{\mathrm{L}}$. To examine this possibility, we examined whether antioxidant inhibitor $\mathrm{N}$-acetylcysteine (NAC), JNK inhibitor SP6001125, HSP90 inhibitor geldanamycin or ATM knockdown inhibit the degradation of $C-F L I P L$ during hyperthermia. Figures $6 c$ and $d$ show that hyperthermia-induced C-FLIPL degradation was independent of ROS, JNK, HSP9O and ATM.

Ubiquitination at Lys-195 promoted C-FLIP $\mathrm{L}_{\mathrm{L}}$ reduction and enhancement of Mapa-mediated apoptosis. To determine the residues implicated in ubquitination-mediated C-FLIP $\mathrm{P}_{\mathrm{L}}$ proteolysis, we first narrowed down the region of $C-F_{L} P_{L}$ involved in hyperthermia-induced degradation. Initially, we constructed three fragments of C-FLIP , including 1-200 aa, 1-240 aa and 240-480 aa. After transfection of the corresponding expression vectors, we assessed the stability of the resulting fragments in response to hyperthermia. The fragment spanning amino acid (aa) 1-200 was reduced, indicating that the 1-200-aa region of $C-F L I P_{L}$ conferred instability after hyperthermia (Figure 7a). The online software UbPred (University of California, San Diego, CA, USA), which is a predictor of protein ubiquitination sites, showed that lysine 106 and 195 had the highest score among the 19 lysines in the 1-200-aa region. As lysine is the aa where ubquitination moieties are ligated, we replaced 106 and 195 lysine to arginine and tested the stability of the fulllength $C-F L I P_{L}$ carrying the resulting point mutation. As shown in Figure $7 \mathrm{~b}$, in the transfection group, $\mathrm{C}-\mathrm{FLIP}_{\mathrm{L}}$ lysine 106 arginine (K106R) was easily degraded when subjected to hyperthermia, whereas lysine 195 arginine (K195R) was refractory to degradation by hyperthermia. Figure 7c confirmed that C-FLIPL wild type (WT) was efficiently ubiquitinated but not the K195R mutant, which was found virtually without ubiquitination. Finally, we compared the sensitization of hyperthermia with Mapa in the CX-1 c-FLIP WT and K195R transient transfectants in PARP cleavage (apoptosis) and cell viability. We observed that c-FLIPL K195R-expressing cells were resistant to Mapa in combination hyperthermia-induced apoptotic cell death (Figures 7d and e). These results suggest that the transient hyperthermia-mediated degradation of $\mathrm{c}-\mathrm{FLIP}_{\mathrm{L}}$ involved ubiquitination of K195, and K195R mutant conferred resistance against hyperthermia-augmented Mapa-induced apoptotic death.

\section{Discussion}

Our laboratory has developed strategies for thermal sensitization in an attempt to improve the clinical efficacy of IHP. We previously reported that hyperthermia has a synergistic effect with Mapa or TRAIL in causing cytotoxicity through the mitochondria-dependent pathway. ${ }^{28,29}$ However, there was a large amount of activated caspase 8 in the combination therapy (Figure 1d), indicating that the extrinsic apoptotic pathway was also activated by hyperthermia in colon cancer cells. Thus, our interest was to extend our inquiry to solve the molecular mechanisms for the extrinsic pathway in hyperthermia-enhanced apoptotic death.

c-FLIP, also known as FLAME-1/I-FLICE/CASPER/CASH/ MRIT/CLARP/Usurpin, is a well-described inhibitor of DRmediated apoptosis. C-FLIP was first described in 1997, and has been shown to be a major inhibitor of procaspase 8 activation at the DISC. The three c-FLIP isoforms comprise: Long (L), Short (S) and Raji (R). All three isoforms possess two DED domains and thereby bind to the DISC. The short FLIP isoforms, c-FLIP $S_{S}$ and $c-$ FLIP $_{R}$, behave as pure inhibitors of procaspase 8 activation. ${ }^{30}$ However, the function of $\mathrm{C}-\mathrm{FLIP} \mathrm{P}$ is controversial. It can act as an anti-apoptotic molecule or pro-apoptotic molecule. ${ }^{31,32}$ Whether $\mathrm{C}-$ FLIP $_{\mathrm{L}}$ accelerates or slows down DR-induced cell death does not only depend on its amount, but also on the cell type and the strength of receptor stimulation. ${ }^{33}$ Our experiments with CX-1 cells stably overexpressing C-FLIPL showed that 


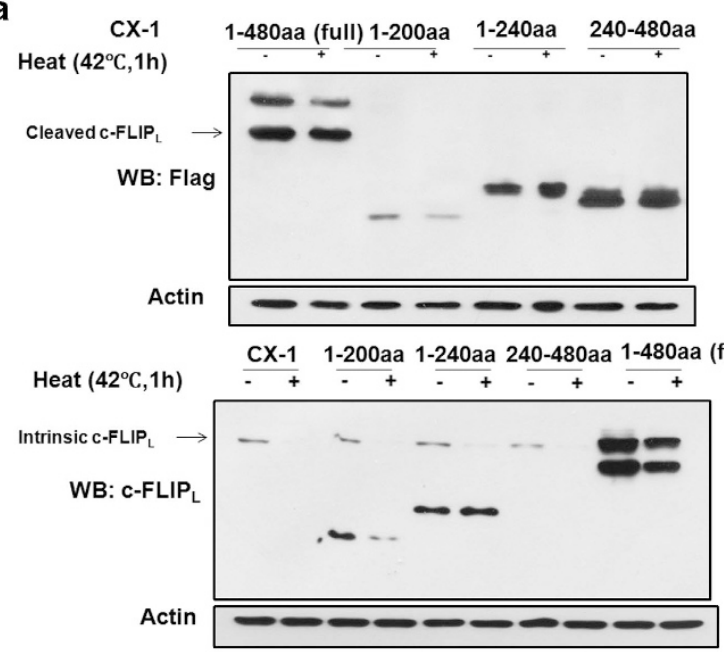

b

UbPred: predictor of ubiquitination sites (1-200aa)

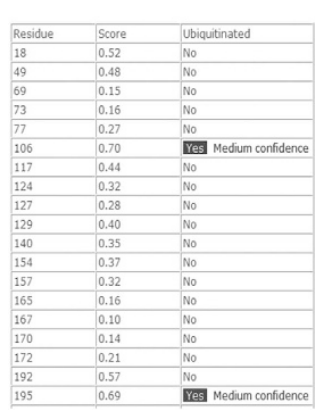

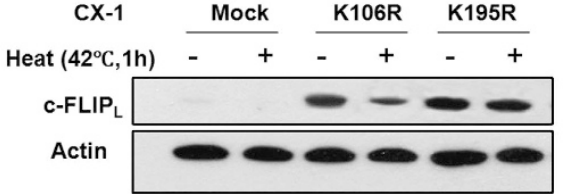

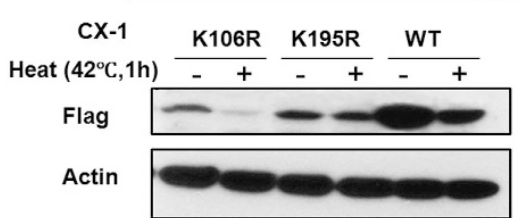

C $\quad$ C-FLIP $P_{L}$ WT $\quad$ C-FLIP $K 195 R$ Heat $\left(42^{\circ} \mathrm{C}, 1 \mathrm{~h}\right) \stackrel{+}{-+}$

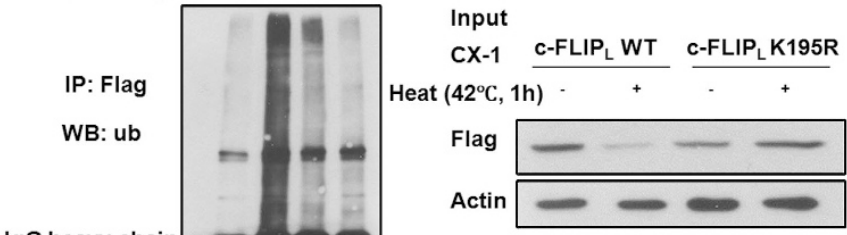

IgG light chain

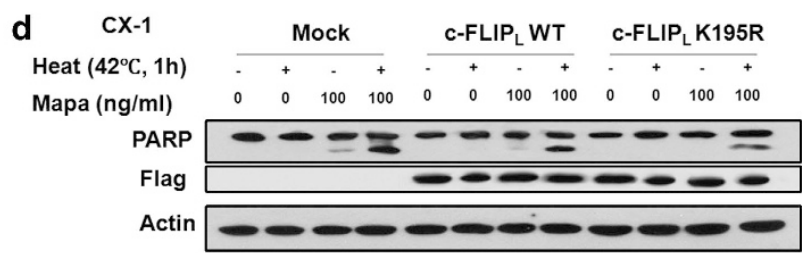

e

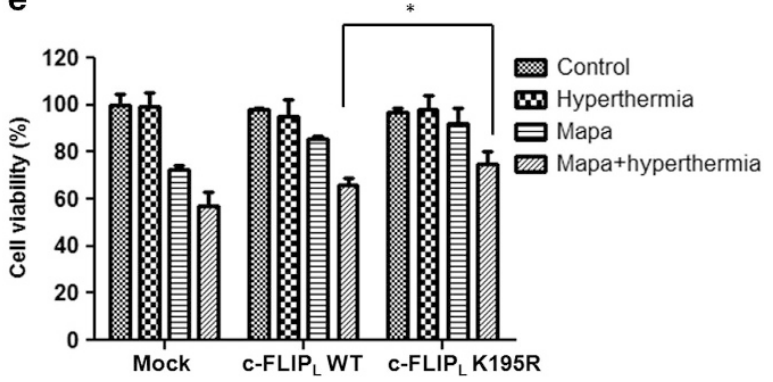

Figure 7 Ubiquitination of C-FLIP $P_{L}$ at Lys-195 was required for the downregulation of C-FLIP and the enhancement of Mapa-mediated apoptosis. (a) CX-1 cells were transiently transfected with plasmids containing Flag-tagged c-FLIP $(1-480,1-200,1-240$ and $240-480 \mathrm{aa})$. After $48 \mathrm{~h}$ incubation, the effect of hyperthermia at $42^{\circ} \mathrm{C}$ for $1 \mathrm{~h}$ on the level of C-FLIP fragments was examined by western blot using an antibody to recognize Flag or N-terminal c-FLIP. (b) Potential ubiquitination sites (Lys-106 and Lys-195) were predicted by the software UbPred, and the point mutations (Lys to Arg (K to R)) were introduced into two lysine residues from 1-200 aa of C-FLIPL. CX-1 cells were transiently transfected with $4 \mu \mathrm{g}$ plasmid containing mock, K106R, K195R, or WT C-FLIPL. After $48 \mathrm{~h}$ incubation, cells were exposed to hyperthermia at $42{ }^{\circ} \mathrm{C}$ for $1 \mathrm{~h}$. The level of C-FLIPL was detected by NF6 (upper panel) or anti-Flag (lower panel) antibody. Actin was used as an internal control. (c) CX-1 cells were transiently transfected with WT C-FLIP ${ }_{L}$ and K195R plasmid; $48 \mathrm{~h}$ later, cells were subjected to hyperthermia at $42^{\circ} \mathrm{C}$ for $1 \mathrm{~h}$. The levels of ubiquitinated c-FLIP $\mathrm{P}_{\mathrm{L}}$ were detected by IP with anti-Flag antibody, followed by western blot using anti-ubiquitin antibody. The presence of transfected c-FLIP $P_{L}$ in the lysates was verified by western blot. Actin was shown as an internal standard. (d) CX-1 cells were transiently transfected with WT C-FLIPL and K195R plasmid; $48 \mathrm{~h}$ later, cells were heated at $42^{\circ} \mathrm{C}$ for $1 \mathrm{~h}$ in the presence or absence of Mapa $(100 \mathrm{ng} / \mathrm{ml})$, and then incubated at $37^{\circ} \mathrm{C}$ for $3 \mathrm{~h}$. Lysates containing equal amounts of protein were immunoblotted with anti-PARP antibody. Actin was shown as an internal standard. (e) CX-1 cells were transiently transfected with c-FLIPL WT and K195R plasmid; $48 \mathrm{~h}$ later, cells were heated at $42^{\circ} \mathrm{C}$ for $1 \mathrm{~h}$ in the absence or presence of Mapa $(100 \mathrm{ng} / \mathrm{ml})$, and then incubated for $72 \mathrm{~h}$ at $37^{\circ} \mathrm{C}$. Cell viability was analyzed by MTS assay. Error bars represented S.D. from triplicate experiments. Asterisk (*) represents a statistically significant difference $(P<0.05)$

overexpression of $c-F L I P L$ was able to rescue cells from hyperthermia-induced sensitization to Mapa-mediated apoptosis, indicating that $\mathrm{C}-\mathrm{FLIP} \mathrm{P}_{\mathrm{L}}$ functioned as an antiapoptotic molecule (Figure 4b).

Among the colon cancer cell lines we have tested, c-FLIP was hardly detected, whereas the amount of $C-F L I P L$ was relatively high. In addition, Meinander et al. ${ }^{34}$ demonstrated that hyperthermia influenced the rate of lymphocyte elimination through depletion of $\mathrm{c}-\mathrm{FLIP}_{\mathrm{s}}$, but the involvement of $C-F L I P L$ was not clear. Thus, we focused on the role of $c-F L I P_{L}$ in the synergistic induction of apoptotic death by hyperthermia, in combination with Mapa in colon cancer cells.

We showed in this study that C-FLIP level was dramatically reduced, following hyperthermia in human colorectal cancer CX-1 and HCT116 cells, several colon cancer stem cells, breast cancer cells and MEF cells, indicating that hyperthermia reduction of $C-F L I P_{L}$ is a general principle, albeit at cell-specific levels. We observed the sensitizing effect of hyperthermia on Mapa-mediated apoptosis was reduced when the levels of $C-F L I P_{L}$ were restored during recovery from hyperthermia in CX-1 cells. We also observed the negative correlation between the intracellular levels of $C-F L I P L$ and the synergistic effect of hyperthermia on Mapa-induced apoptosis in various colon cancer cells (Figure 3d). Given the central role of $\mathrm{C}-\mathrm{FLIP}_{\mathrm{L}}$ in extrinsic apoptotic death, we investigated in depth the mechanism of FLIP $P_{L}$ downregulation by hyperthermia.

Transcriptionally, c-FLIP expression is known to be regulated by several transcription factors, including $\mathrm{NF}-\kappa \mathrm{B}$ and p53. ${ }^{35,36}$ In this study, data from qRT-PCR showed that 
the transcription of c-FLIP was constant during hyperthermia in CX-1 cells. C-FLIP expression level is also greatly regulated by post-transcriptional mechanisms. Several researchers have reported that c-FLIP expression is regulated by JNK-mediated phosphorylation, as well as the activation of Itch, ${ }^{22-24}$ or by the ATM kinase, ${ }^{26,27}$ or ROS. ${ }^{25}$ However, other researchers have observed JNK-independent, Itch-independent degradative mechanisms of C-FLIP. ${ }^{37,38}$ In this study, we observed that the downregulation of FLIP $\mathrm{P}_{\mathrm{L}}$ by hyperthermia in CX-1 cells is JNK-independent, Itchindependent, ATM-independent and ROS-independent. Thus, these discrepancies need to be further studied for clarification.

c-FLIP has been shown to be ubiquitinated and degraded via the proteasome or a lysosomal pathway..$^{20,21,39}$ Data from Figure $5 \mathrm{c}$ illustrate that the proteasome inhibitor MG132 inhibited the hyperthermia-mediated downregulation of C-FLIP $\mathrm{L}_{\mathrm{L}}$, but there was no restoration of $\mathrm{C}-\mathrm{FLIP}_{\mathrm{L}}$ for lysosomal proteases inhibitor $\mathrm{NH}_{4} \mathrm{Cl}$, confirming the existence of proteasome-mediated, but not lysosome-mediated, degradation of the protein. Ubiquitination assays further proved that the ubiquitination of $\mathrm{C}-\mathrm{FLIP}_{\mathrm{L}}$ increased upon hyperthermia.

Ubiquitination is a post-translational modification used by cells to alter protein stability and function. ${ }^{40}$ Protein ubiquitination is accomplished by the coordinated action of a series of proteins referred to as E1, E2 and E3 enzymes. E1 activates ubiquitination, triggering its transfer onto the Ub carrier enzyme E2, which in turn is transferred onto a substrate protein by an E3 ligase and the moiety becomes covalently linked. The repeated addition of ubiquitination moieties results in the formation of a polyubiquitinated substrate protein, which is recognized by a large proteolytic complex, the $26 \mathrm{~S}$ proteasome. The Itchs (of which over 1000 are encoded in the human genome) catalyze the rate-limiting step of the process and facilitate the transfer of the activated ubiquitin protein to lysine $(\mathrm{K})$ in the target protein. ${ }^{41,42}$

As Itch is not likely the E3 ligase for hyperthermia, it is worth discovering the lysine residues involved in the $C-F L I P_{L}$ ubiquitination, which will help to determine the E3 ligase of C-FLIP $\mathrm{P}_{\mathrm{L}}$ after hyperthermia and may contribute to the sensitization. Serine 193 was reported to regulate c-FLIPs but not C-FLIP ubiquitination and stability. ${ }^{43}$ Lysines 192 and 195 were reported as C-FLIPS ubiquitination sites but not C-FLIP $P_{L}$ by hemin treatment. ${ }^{44}$ Thus, it is worthwhile to investigate the ubiquitination site of $C-F_{L} P_{L}$ by hyperthermia. In this study, the fragment analysis showed that the 1-200-aa region of $\mathrm{C}-\mathrm{FLIP} \mathrm{L}$ conferred instability after hyperthermia; however, unexpectedly, the fragment 1-240 aa was stable when exposed to hyperthermia (Figure 7a). It is possible that the C-terminal of 1-240 aa covered the ubiquitination site of 1-200 aa and consequently disrupted the reliability of the hyperthermia.

The fragment ubquitination assay and the online software UbPred narrowed down the possible ubquitination site, and we found that K195 was responsible for ubiquitination, and thus degradation of c-FLIP $\mathrm{L}_{\mathrm{L}}$ by hyperthermia. K195R transient transfectants partially protected from the hyperthermiainduced sensitization to Mapa-mediated apoptosis, indicating that other factors or pathways were still involved, which was in accord with our previous publication.
Taken together, we document here that hyperthermia may trigger a fast and robust reduction in C-FLIP $P_{L}$ stability that the sensitization of Mapa induced by hyperthermia was a consequence of increased proteasomal degradation of FLIP and that the residue $\mathrm{K} 195$ was responsible for $\mathrm{C}-\mathrm{FLIP} \mathrm{P}_{\mathrm{L}}$ ubiquitination. Such a general regulatory mechanism has broad ramifications for hyperthermia-mediated regulation of apoptosis. As this combination has an excellent translational potential, it should be considered for colorectal hepatic metastases treatment in clinics.

\section{Materials and Methods}

Cell cultures. Human colorectal carcinoma CX-1 cells, obtained from Dr. JM Jessup (National Institutes of Health), breast cancer cells MDA-MB-231 and MDAMB-453 (American Type Culture Collection, Manassas, VA, USA) and their ATM-knockdown (shATM) cells were cultured in RPMI-1640 medium (Gibco BRL, Gaithersburg, MD, USA) containing $10 \%$ fetal bovine serum (HyClone, Logan, UT, USA). The human colorectal carcinoma HCT116 cell line, kindly provided by Dr. B Vogelstein (Johns Hopkins University) and the human colon adenocarcinoma HT-29 (ATCC) cell line were cultured in McCoy's 5A medium (Gibco-BRL) containing 10\% fetal bovine serum. Human colon cancer stem cells, Tu-22, Tu-12 and $\mathrm{Tu}-21^{45}$ were established by Dr. E Lagasse (University of Pittsburgh) and cultured in DMEM/F12 medium (Gibco BRL) containing $0.5 \%$ fetal bovine serum (HyClone) and $1 \%$ insulin, transferrin and selenium (I.T.S, Fisher Scientific, Pittsburgh, PA, USA). MEF and its UBR1/2 DKO (ubiquitin-protein ligase E3 component $\mathrm{N}$-recognin 1 and 2 double knockout) cells were obtained from Dr. YT Kwon (University of Pittsburgh) and cultured in DMEM medium (Gibco BRL) containing $10 \%$ fetal bovine serum. All the cells were kept in a $37^{\circ} \mathrm{C}$ humidified incubator with $5 \% \mathrm{CO}_{2}$.

Reagents and antibodies. $\mathrm{MG} 132, \mathrm{NH}_{4} \mathrm{Cl}, \mathrm{CHX}, \mathrm{NAC}$, geldanamycin and protease inhibitor cocktail were obtained from Sigma Chemical Co (St. Louis, MO, USA). JNK inhibitor (SP600125) and G418 were from Calbiochem (La Jolla, CA, USA). Mapa was obtained from Human Genome Sciences (Rockville, MD, USA). Anti-Flag, anti-caspase 8, anti-caspase 9, anti-caspase 3, anti-ubiquitin and antiPARP antibody were from Cell Signaling (Danvers, MA, USA). Anti-FLIP (NF6) was purchased from Enzo Life Sciences (Farmingdale, NY, USA). Anti-ltch was purchased from BD Biosciences (Franklin Lakes, NJ, USA). Anti-actin antibody was obtained from Santa Cruz Biotechnology (Santa Cruz, CA, USA).

Hyperthermia treatment and transient transfection. For hyperthermia, cells cultured in $35-\mathrm{mm}$ or $100-\mathrm{mm}$ dishes were sealed with parafilm and were placed in a circulating water bath (Heto, Thomas Scientific, Denmark), which was maintained within $0.02{ }^{\circ} \mathrm{C}$ of the desired temperature. For transient transfection, cells were transfected with Lipofectamine 2000 (Invitrogen, Carlsbad, CA, USA) and were treated with hyperthermia in the presence or absence of Mapa, $48 \mathrm{~h}$ after transfection.

MTS 3-(4,5-dimethylthiazol-2-yl)-5-(3-carboxymethoxyphenyl)2-(4-sulfophenyl)-2H-tetrazolium assays. MTS studies were carried out using the Promega CellTiter 96 AQueous One Solution Cell Proliferation Assay (Promega, Madison, WI, USA). CX-1 cells were grown in tissue culture-coated 96-well plates, and treated as described in results. Cells were then treated with the MTS/phenazine methosulfate solution for $1 \mathrm{~h}$ at $37^{\circ} \mathrm{C}$. Absorbance at $490 \mathrm{nmol} / \mathrm{l}$ was determined using an enzyme-linked immunosorbent assay plate reader. Data are reported as percent viable tumor cells as compared with the untreated cells.

Annexin $\mathbf{V}$ binding. Cells were heated in the absence or presence of Mapa and harvested by trypsinization, washed with serum-free medium and suspended in PBS at the density $1 \times 10^{6}$ cells $/ \mathrm{ml}$. Aliquots of $1 \times 10^{5}$ cells were suspended in binding buffer (Annexin V-fluorescein isothiocyanate (FITC) Staining Kit, BD Pharmingen, San Diego, CA, USA). This cell suspension was stained with mouse anti-human Annexin V antibody and propidium iodide (PI) for 15 min in the dark. The immunostaining was terminated by addition of binding buffer, and cells were immediately analyzed by the AccuriC6 Flow Cytometer (Accuri Cytometers, Ann Arbor, MI, USA). Typically, 100000 events were collected using 
excitation/emission wavelengths of $488 / 525$ and $488 / 675 \mathrm{~nm}$ for Annexin $\mathrm{V}$ and $\mathrm{PI}$, respectively. Results were analyzed with VenturiOne software (Applied Cytometry, Sacramento, CA, USA).

Cell cycle analysis. Cells were harvested and fixed with $70 \%$ ethanol overnight. Cells were stained with PI/RNase staining buffer (BD Pharmingen) for $15 \mathrm{~min}$ at room temperature, subjected to flow cytometry (AccuriC6 Flow Cytometer, Accuri Cytometers) and analyzed by Flowjo7.6.1 software (Tree Star Inc., Ashland, VA, USA).

Knockdown of c-FLIP with siRNA oligomers. To generate c-FLIP-knockdown CX-1 cells, cells were transfected with $10 \mathrm{nM}$ of siRNA FLIP (a pool of four target-specific 19-25 nt) and control siRNA from Santa Cruz Biotechnology, using Lipofectamine 2000 (Invitrogen). Expression levels were determined by immunoblot analysis.

Knockdown of itch with shRNA lentiviral infection. Itch shRNA lentivirus vectors were obtained from Santa Cruz Biotechnology along with the appropriate control vector. The infection procedure was performed according to the instructions provided by the company. After infection, stable clones were selected by treatment with puromycin. Itch knockdown levels were assessed by immunoblot analysis.

Quantitative reverse transcription-PCR analysis. Total RNA was extracted and purified from cultured cells using the RNeasy Mini Kit (Qiagen, Valencia, CA, USA), according to the manufacturer's instructions. The RNA was quantified by determining absorbance at $260 \mathrm{~nm}$. Two micrograms of total RNA from each sample was reverse transcribed into CDNA using the High-Capacity cDNA Reverse Transcription Kit (Life Technologies Inc., Frederick, MD, USA) in a volume of $20 \mu \mathrm{l}$. qPCR was carried out using Applied Biosystems' (Carlsbad, CA, USA) inventoried TaqMan assays (20X Primer Probe mix), corresponding to CASP8- and FADD-like apoptosis regulator (CFLAR; assay ID Hs00153439 m1) and glyceraldehyde-3-phosphate dehydrogenase (GAPDH; assay ID Hs02758991_g1). All reactions were carried out with 2X TaqMan Universal PCR Master Mix (Applied Biosystems) on an Applied Biosystems StepOne Plus Real-Time PCR System, according to the standard protocols. The amount of each target gene relative to the housekeeping gene GAPDH was determined using the comparative threshold cycle (Ct) method (Applied Biosystems User Bulletin 2, http://docs.appliedbiosystems.com/pebiodocs/04303859.pdf).

Immunoprecipitation. Briefly, cells were lysed in CHAPS lysis buffer with protease inhibitor cocktail (Calbiochem). Cell lysates were clarified by centrifugation at 13000 r.p.m. for $15 \mathrm{~min}$, and protein concentration was determined by BCA Protein Assay Reagent (Pierce Biotechnology, Rockford, IL, USA). For immunoprecipitation, $0.5-1 \mathrm{mg}$ of lysate was incubated with $1.5 \mu \mathrm{g}$ of rabbit antiBax or anti-Flag antibody or rabbit IgG (Santa Cruz Biotechnology) at $4^{\circ} \mathrm{C}$ overnight, followed by the addition of protein A-agarose beads (Santa Cruz Biotechnology) and rotation at room temperature for $2 \mathrm{~h}$. The beads were washed and resuspended in SDS sample buffer; this was followed by an immunoblot analysis.

Immunoblot analysis. Cells were lysed with Laemmli lysis buffer $(2.4 \mathrm{M}$ glycerol, $0.14 \mathrm{M}$ Tris, pH 6.8, 0.21 M SDS, $0.3 \mathrm{mM}$ bromophenol blue) and boiled for $10 \mathrm{~min}$. Protein content was measured with BCA Protein Assay Reagent. The samples were diluted with $1 \times$ lysis buffer containing $1.28 \mathrm{M} \beta$-mercaptoethanol, and equal amounts of protein were loaded on $8-12 \%$ SDS-polyacrylamide gels. Proteins were separated by SDS-PAGE and electrophoretically transferred to nitrocellulose membrane. The nitrocellulose membrane was blocked with $5 \%$ nonfat dry milk in PBS-Tween-20 $(0.1 \%, v / v)$ for $1 \mathrm{~h}$. The membrane was incubated with primary antibody (diluted according to the manufacturer's instructions) at room temperature for $2 \mathrm{~h}$. Horseradish peroxidase-conjugated anti-rabbit or anti-mouse IgG was used as the secondary antibody. Immunoreactive protein was visualized by the chemiluminescence protocol (ECL, Amersham, Arlington Heights, IL, USA). To ensure equal protein loading, each membrane was stripped and reprobed with anti-actin antibody to normalize for differences in protein loading.

Fragment construction and cite-directed mutagenesis. Fragments of c-FLIP from 1-200aa, 1-240 aa and 240-480 aa were amplified by PCR from the plasmid pCR3.V64-Met-Flag-FLIP , a gift from Dr. J Tschopp (University of
Lausanne). All amplified products were further cloned into the EcoRI/Xhol site of pCRIII vector to generate C-FLIP fragments 1-200 aa, 1-240 aa and 240-480 aa. Fragment constructs were confirmed by DNA sequencing. Lys 106 to $\operatorname{Arg}(\mathrm{K} 106 \mathrm{R})$ and $K 195 R$ mutations were introduced into the $C-F L I P_{L}$ gene using fully complementary mutagenic primers (QuickChange site-directed mutagenesis kit, Agilent Technologies, Santa Clara, CA, USA). The following mutagenizing oligonucleotides were used: sense $5^{\prime}$-GAGATTGGTGAGGATTTGGATAGATCTG ATGTGTCCTCATTAAT- $3^{\prime}$ and antisense $5^{\prime}$-ATTAATGAGGACACATCAGATCT AT-CCAAATCCTCACCAATCTC-3' for K106R mutant, sense 5'-CAAGCAGCAA TCCA-AAAGAGTCTCAGGGATCCTTCAAAT- $3^{\prime}$ and antisense 5'-ATTTGAAGGA TCCCTGAG-ACTCTTTTGGATTGCTGCTTG-3' for K195R mutant. Mutants were confirmed by sequence analysis.

Statistical analysis. Statistical analysis was carried out using Graphpad InStat 3 software (GraphPad Software, San Diego, CA, USA). Statistical significance is marked with asterisks $\left({ }^{*} P<0.05\right.$ and $\left.{ }^{* *} P<0.01\right)$.

\section{Conflict of Interest}

The authors declare no conflict of interest.

Acknowledgements. We thank Dr. Patrick Kaminker from Human Genome Sciences who provided us with mapatumumab. This work was supported by the following Grants: NCl Grant R01 CA140554 (YJ L), R01 HL083365 (YTK) and R01 DK085711 (EL), DOD-CDMRP Grant BC103217:W81XWH-11-1-0128 (YJL), and World Class University R31-2008-000-10103-0 (YTK). This project used the UPCI Core Facility and was supported in part by award P30CA047904.

\section{Author Contributions}

$X S$ and YJL conceived and designed the experiments. XS and SYK performed the experiments. XS, ZZ and YJL analyzed the data. LE and YTK contributed reagents, materials and analysis tools, and XS and YJL wrote the paper.

1. Ruers T, Bleichrodt RP. Treatment of liver metastases, an update on the possibilities and results. Eur J Cancer 2002; 38: 1023-1033.

2. Hafstrom LR, Holmberg SB, Naredi PL, Lindner PG, Bengtsson A, Tidebrant G et al. Isolated hyperthermic liver perfusion with chemotherapy for liver malignancy. Surg Oncol 1994; 3: 103-108.

3. Alexander HR Jr, Libutti SK, Pingpank JF, Bartlett DL, Helsabeck C, Beresneva T. Isolated hepatic perfusion for the treatment of patients with colorectal cancer liver metastases after irinotecan-based therapy. Ann Surg Oncol 2005; 12: 138-144.

4. Varghese S, Xu H, Bartlett D, Hughes M, Pingpank JF, Beresnev T et al. Isolated hepatic perfusion with high-dose melphalan results in immediate alterations in tumor gene expression in patients with metastatic ocular melanoma. Ann Surg Oncol 2010; 17: $1870-1877$.

5. Zeh 3rd HJ, Brown CK, Holtzman MP, Egorin MJ, Holleran JL, Potter DM et al. A phase I study of hyperthermic isolated hepatic perfusion with oxaliplatin in the treatment of unresectable liver metastases from colorectal cancer. Ann Surg Oncol 2009; 16: 385-394.

6. Mom CH, Verweij J, Oldenhuis CN, Gietema JA, Fox NL, Miceli R et al. Mapatumumab, a fully human agonistic monoclonal antibody that targets TRAIL-R1, in combination with gemcitabine and cisplatin: a phase I study. Clin Cancer Res 2009; 15: 5584-5590.

7. Younes A, Vose JM, Zelenetz AD, Smith MR, Burris HA, Ansell SM et al. A phase $1 \mathrm{~b} / 2$ trial of mapatumumab in patients with relapsed/refractory non-Hodgkin's lymphoma. Br J Cancer 2010; 103: 1783-1787.

8. Trarbach T, Moehler M, Heinemann V, Kohne CH, Przyborek M, Schulz C et al. Phase II trial of mapatumumab, a fully human agonistic monoclonal antibody that targets and activates the tumour necrosis factor apoptosis-inducing ligand receptor-1 (TRAIL-R1), in patients with refractory colorectal cancer. Br J Cancer 2010; 102: 506-512.

9. Zhang L, Fang B. Mechanisms of resistance to TRAIL-induced apoptosis in cancer. Cancer Gene Ther 2005; 12: 228-237.

10. Krueger A, Baumann S, Krammer PH, Kirchhoff S. FLICE-inhibitory proteins: regulators of death receptor-mediated apoptosis. Mol Cell Biol 2001; 21: 8247-8254.

11. Lavrik IN, Krammer PH. Regulation of CD95/Fas signaling at the DISC. Cell Death Differ 2012; 19: 36-41.

12. Irmler M, Thome M, Hahne M, Schneider P, Hofmann K, Steiner V et al. Inhibition of death receptor signals by cellular FLIP. Nature 1997; 388: 190-195.

13. Wilson TR, McLaughlin KM, McEwan M, Sakai H, Rogers KM, Redmond KM et al. c-FLIP: a key regulator of colorectal cancer cell death. Cancer Res 2007; 67: 5754-5762.

14. Ullenhag GJ, Mukherjee A, Watson NF, Al-Attar AH, Scholefield JH, Durrant LG. Overexpression of FLIPL is an independent marker of poor prognosis in colorectal cancer patients. Clin Cancer Res 2007; 13: 5070-5075. 
15. Longley DB, Wilson TR, McEwan M, Allen WL, McDermott U, Galligan L et al. c-FLIP inhibits chemotherapy-induced colorectal cancer cell death. Oncogene 2006; 25: 838-848.

16. Yoo J, Kim HR, Lee YJ. Hyperthermia enhances tumour necrosis factor-related apoptosisinducing ligand (TRAIL)-induced apoptosis in human cancer cells. Int J Hyperther 2006; 22: 713-728.

17. Yoo J, Lee YJ. Effect of hyperthermia and chemotherapeutic agents on TRAIL-induced cell death in human colon cancer cells. J Cell Biochem 2008; 103: 98-109.

18. Song X, Kim HC, Kim SY, Basse P, Park BH, Lee BC et al. Hyperthermia-enhanced TRAIL- and mapatumumab-induced apoptotic death is mediated through mitochondria in human colon cancer cells. J Cell Biochem 2012; 113: 1547-1558.

19. Goldberg AL. Protein degradation and protection against misfolded or damaged proteins. Nature 2003; 426: 895-899.

20. Scudiero I, Zotti T, Ferravante A, Vessichelli M, Reale C, Masone MC et al. Tumor necrosis factor (TNF) receptor-associated factor 7 is required for TNF alpha-induced Jun NH2terminal kinase activation and promotes cell death by regulating polyubiquitination and lysosomal degradation of c-FLIP protein. J Biol Chem 2012; 287: 6053-6061.

21. Kim Y, Suh N, Sporn M, Reed JC. An inducible pathway for degradation of FLIP protein sensitizes tumor cells to TRAIL-induced apoptosis. J Biol Chem 2002; 277: 22320-22329.

22. Chang L, Kamata H, Solinas G, Luo JL, Maeda S, Venuprasad K et al. The E3 ubiquitin ligase itch couples JNK activation to TNF alpha-induced cell death by inducing c-FLIP(L) turnover. Cell 2006; 124: 601-613.

23. Abedini MR, Muller EJ, Brun J, Bergeron R, Gray DA, Tsang BK. Cisplatin induces p53-dependent FLICE-like inhibitory protein ubiquitination in ovarian cancer cells. Cancer Res 2008; 68: 4511-4517.

24. Yang F, Tay KH, Dong L, Thorne RF, Jiang CC, Yang E et al. Cystatin B inhibition of TRAIL-induced apoptosis is associated with the protection of FLIP $(L)$ from degradation by the E3 ligase itch in human melanoma cells. Cell Death Differ 2010; 17: 1354-1367.

25. Wang L, Azad N, Kongkaneramit L, Chen F, Lu Y, Jiang BH et al. The Fas death signaling pathway connecting reactive oxygen species generation and FLICE inhibitory protein down-regulation. J Immunol 2008; 180: 3072-3080.

26. Stagni V, di Bari MG, Cursi S, Condo I, Cencioni MT, Testi R et al. ATM kinase activity modulates Fas sensitivity through the regulation of FLIP in lymphoid cells. Blood 2008; 111: 829-837.

27. Stagni V, Mingardi M, Santini S, Giaccari D, Barila D. ATM kinase activity modulates cFLIP protein levels: potential interplay between DNA damage signalling and TRAIL-induced apoptosis. Carcinogenesis 2010; 31: 1956-1963.

28. Yoo J, Lee YJ. Effect of hyperthermia on TRAIL-induced apoptotic death in human colon cancer cells: development of a novel strategy for regional therapy. J Cell Biochem 2007; 101: 619-630.

29. Alcala MA Jr., Park K, Yoo J, Lee DH, Park BH, Lee BC et al. Effect of hyperthermia in combination with TRAIL on the JNK-Bim signal transduction pathway and growth of xenograft tumors. J Cell Biochem 2010; 110: 1073-1081.

30. Krueger A, Schmitz I, Baumann S, Krammer PH, Kirchhoff S. Cellular FLICE-inhibitory protein splice variants inhibit different steps of caspase-8 activation at the CD95 deathinducing signaling complex. J Biol Chem 2001; 276: 20633-20640.

31. Yu JW, Shi Y. FLIP and the death effector domain family. Oncogene 2008; 27: 6216-6227.
32. Chang DW, Xing Z, Pan Y, Algeciras-Schimnich A, Barnhart BC, Yaish-Ohad S et al. cFLIP $(L)$ is a dual function regulator for caspase-8 activation and CD95-mediated apoptosis. EMBO J 2002; 21: 3704-3714.

33. Fricker N, Beaudouin J, Richter P, Eils R, Krammer PH, Lavrik IN. Model-based dissection of CD95 signaling dynamics reveals both a pro- and antiapoptotic role of C-FLIPL. J Cell Biol 2010; 190: 377-389.

34. Meinander A, Soderstrom TS, Kaunisto A, Poukkula M, Sistonen L, Eriksson JE. Fever-like hyperthermia controls $\mathrm{T}$ Lymphocyte persistence by inducing degradation of cellular FLIPshort. J Immunol 2007; 178: 3944-3953.

35. Micheau O, Lens S, Gaide O, Alevizopoulos K, Tschopp J. NF-kappaB signals induce the expression of c-FLIP. Mol Cell Biol 2001; 21: 5299-5305.

36. Bartke T, Siegmund D, Peters N, Reichwein M, Henkler F, Scheurich $P$ et al. p53 upregulates CFLIP, inhibits transcription of NF-kappaB-regulated genes and induces caspase-8-independent cell death in DLD-1 cells. Oncogene 2001; 20: 571-580.

37. Chen S, Cao W, Yue P, Hao C, Khuri FR, Sun SY. Celecoxib promotes c-FLIP degradation through Akt-independent inhibition of GSK3. Cancer Res 2011; 71: 6270-6281.

38. Lin $Y$, Liu X Yue $P$, Benbrook DM, Berlin KD, Khuri FR et al Involvement of c-FLIP and survivin down-regulation in flexible heteroarotinoid-induced apoptosis and enhancement of TRAIL-initiated apoptosis in lung cancer cells. Mol Cancer Ther 2008; 7: 3556-3565.

39. Fukazawa T, Fujiwara T, Uno F, Teraishi F, Kadowaki $Y$, Itoshima $T$ et al. Accelerated degradation of cellular FLIP protein through the ubiquitin-proteasome pathway in p53-mediated apoptosis of human cancer cells. Oncogene 2001; 20: 5225-5231.

40. Hoeller D, Hecker CM, Dikic I. Ubiquitin and ubiquitin-like proteins in cancer pathogenesis Nat Rev Cancer 2006; 6: 776-788.

41. Hochstrasser M. Origin and function of ubiquitin-like proteins. Nature 2009; 458: 422-429.

42. Staub O, Rotin D. Role of ubiquitylation in cellular membrane transport. Physiol Rev 2006; 86: $669-707$.

43. Kaunisto A, Kochin V, Asaoka T, Mikhailov A, Poukkula M, Meinander A et al. PKCmediated phosphorylation regulates c-FLIP ubiquitylation and stability. Cell Death Differ 2009; 16: 1215-1226.

44. Poukkula M, Kaunisto A, Hietakangas V, Denessiouk K, Katajamaki T, Johnson MS et al. Rapid turnover of c-FLIPshort is determined by its unique C-terminal tail. J Biol Chem 2005; 280: 27345-27355.

45. Odoux C, Fohrer H, Hoppo T, Guzik L, Stolz DB, Lewis DW et al. A stochastic model for cancer stem cell origin in metastatic colon cancer. Cancer Res 2008; 68: $6932-6941$.

(c) (1) (2)(2) Cell Death and Disease is an open-access journal BY NC SA published by Nature Publishing Group. This work is licensed under a Creative Commons Attribution-NonCommercialShareAlike 3.0 Unported License. To view a copy of this license, visit http://creativecommons.org/licenses/by-nc-sa/3.0/ 